\title{
Staphylococcus aureus isolates colonizing and infecting cirrhotic and liver- transplantation patients: comparison of molecular typing and virulence factors
}

\author{
Larissa Marques de Oliveira ${ }^{1,2}$, Inneke Marie van der Heijden ${ }^{1,2}$, George R. Golding ${ }^{3}$, Edson Abdala ${ }^{4}$, \\ Maristela P. Freire ${ }^{4}$, Flavia Rossi ${ }^{5}$, Luiz C. D' alburquerque ${ }^{4}$, Anna S. Levin ${ }^{1,2}$ and Silvia F. Costa ${ }^{2,6^{*}}$
}

\begin{abstract}
Background: S. aureus is an important agent of colonization and infection in liver transplant patients. It harbors several virulence factors that can increase its pathogenicity. However, studies of virulence and molecular typing of MRSA in cirrhotic and liver transplantation patients are scarce.

Results: Here we use SCCmec, PFGE, spa typing, MLST and virulence factors to characterize MRSA isolates in pre and post liver transplantation patients. Sixteen (13\%) of 126 cirrhotic and 15 of the 64 liver-transplanted patients (23\%) were colonized by MRSA $(p=0.091)$. SCCmec types I, II and III that are generally associated with nosocomial infections were identified in $91 \%$ of the isolates. None of the isolates carried PVL, adhesion factors and fib gene. Only three MRSA colonized isolates carried tst gene and were characterized as SCCmec type I and t149. Ten spa types and five STs were identified; t002 and ST105 were the most frequent profiles. Spa types and ST1510 never described in Brazil and a new spa type t14789 were identified. Nineteen PFGE subtypes were found and grouped into nine types. There was a predominant cluster, which was related to the New York/Japanese epidemic clone and harboured SCCmec type II identified in both cirrhotic and post-transplantation patients. Based on SCCmec and virulence factors the MRSA isolates belonged to NY/Jpn clone seen be more similar to the USA100 MRSA isolates.

Conclusions: Although without significance, liver-transplantation was more frequently colonized by MRSA than cirrhotic patients. The most frequent SCCmec was type II, and the predominant cluster was related to the New York/Japanese clone. A new spa t14789, and ST1510 never reported in Brazil were identified.
\end{abstract}

Keywords: Methicillin-resistant Staphylococcus aureus, Colonization, spa typing, PFGE, MLST

\section{Background}

Methicillin-resistant Staphylococcus aureus (MRSA) infections rates have been increasing rapidly worldwide over the past few decades [1]. MRSA is currently endemic in many hospitals in several countries [1]. According to a SENTRY study, in Brazil, the rates of MRSA infections are $\sim 30 \%$ and $S$. aureus is responsible

\footnotetext{
* Correspondence: costasilviaf@ig.com.br

${ }^{2}$ Laboratory of Medical Investigation 54 (LIM-54), Hospital Das Clínicas FMUSP, São Paulo, Brazil

${ }^{6}$ Department of Infectious Diseases, LIM-54, Faculdade de Medicina, University of São Paulo, Avenida Doutor Enéas de Carvalho Aguiar, 470, São Paulo, SP 05403-000, Brazil

Full list of author information is available at the end of the article
}

for $\sim 20 \%$ of nosocomial primary bloodstream infections (BSIs) [2]. MRSA is an important cause of surgical infection in liver transplantation patients, increased duration of hospitalization, costs, morbidity and mortality [3]. Therefore, it is of great importance to understand the epidemiology of MRSA in this population of patients.

Cirrhotic patients are more frequently colonized by MRSA than the general population and the burden of infectious diseases pre and post liver transplantation is clearly attributable to the dysfunction of defensive mechanisms of the host, because of cirrhosis, as well as because of the use of immunosuppressive agents [4]. Several virulence factors present in $S$. aureus that allow 
the adherence, colonization and ability to invade tissues can increase the pathogenicity of this microorganism, among them the Panton-Valentine leucocidin (PVL), a toxin that can be able to make pores in the polymorphonuclear cells [5]. However, studies of virulence of MRSA in cirrhotic and liver transplantation patients are scarce.

Molecular methods such as the characterization of Staphylococcal Chromosome Cassette mec (SCCmec) by polymerase chain reaction (PCR), Multi Locus Sequence Typing (MLST), Pulsed-Field Gel Electrophoresis (PFGE) and Staphylococcus protein A $(S p a)$ typing had been developed to evaluate MRSA isolates and to develop strategies to control and prevent colonization and infection. SCCmec typing is a rapid and easy technique essential for understanding the molecular epidemiology of MRSA [6].

Another widely used tool is PFGE that has an excellent discriminatory power and is very useful for epidemiological studies although it is a laborious and time consuming technique [7]. Spa typing is a more recent method based on sequencing the polymorphic region $\mathrm{X}$ or short-sequence repeat (SSR) region of the gene spa. Changes in the SSR region arise due to deletions, duplications and point mutations, which results in a diverse collection of 'spa types', where each spa type consists of a specific combination of SSRs [8]. Spa typing has been shown to be useful not only for investigation of hospital outbreaks but also for studies of molecular evolution of MRSA [8]. The major advantages of spa typing include it is fast, easy to use, has unambiguous data interpretation and has a standard nomenclature database.

Some studies observed a high concordance between spa types and PFGE epidemic clones [9, 10]. Golding and colleagues showed that the same spa types correspond to multiple PFGE epidemic clones and require additional molecular typing to discriminate them. These authors proposed the use of Panton-Valentine leukocidin and SCCmec typing to differentiate between MRSA isolates that shared the same spa type but presented multiple PFGE epidemic types [10]. However, PVL characterization was not able to differentiate between isolates associated with multiple PFGE epidemic types, although it can be used as a general indicator of PFGE epidemic type.

The aim of this study was to compare the use of molecular methods (SCCmec, PFGE, spa typing and virulence factors) to characterize MRSA isolates that colonized and causing infection in patients before (cirrhotic) and after liver transplantation.

\section{Results}

\section{Study population}

One-hundred and twenty-six outpatients with liver diseases on list waiting for liver transplantation and 64 liver-transplanted patients were evaluated. According to chart reviews and the questionnaire applied to the 126 listed patients, all patients of list transplantation reported go to the hospital at least once a month for doctor visits or routine tests since the discovery of the disease. Furthermore, 47 (37 \%) reported have been hospitalized in the previous 6 months. In addition, 30 (24\%) patients reported previous use of antimicrobials, 58 (46\%) reported not having used any antimicrobial previously and $38(30 \%)$ did not remember about the use of these drugs in the last 6 months. All livertransplanted patients had a 48-hour course of ampicillin plus cefotaxime as antimicrobial prophylaxis and received tacrolimus and steroid as imunossuprevise therapy. Those that developed kidney failure had the therapy replaced by adjusted doses of tacrolimus plus mycophenolate mofetil (MMF) and steroid.

Demographic and clinical data of the study population is shown in Table 1. Sixteen patients of the 126 listed outpatients (13\%) and 15 of the 64 liver-transplanted patients (23\%) were colonized by MRSA $(p=0.091)$. Fourteen patients of list of waiting for liver transplantation were transplanted during the study and were included between the 64 liver-transplanted patients. Among then, two were colonization in pre and post transplantation period and three were colonization only in post transplantation period.

Among 64 liver transplanted patients, five had infections by MRSA (two pneumonias, one infection related to central venous line, one blood stream infection and one peritonitis), three of them evoluted to death. Between them, three patients were colonized in post transplantation period and two patients were colonized in pre and post transplantation period. Only one patient with pneumonia had the same cluster NY/JP in colonization and infection. Twenty-eight (47 \%) liver transplanted patients received steroid plus tacrolimus and 32 (53\%) MMF plus steroid and tacrolimus as immunosuppressive therapy, MRSA colonization was respectively 7 of $28(46 \%)$ and 8 of 32 $(53 \%)$ patients $(p=0.60)$, data of four patients were not available.

\section{Isolates}

Forty-three isolates from 31 patients were identified as MRSA. All isolates were positive for the mecA and $c o \mathrm{~A}$ genes. All isolates were epidemiologically defined as HA-MRSA.

Only one isolate per patient was selected for further molecular typing. When patients had MRSA isolates from the both sites with the same PFGE, the nasal MRSA isolate was choose for next steps. Furthermore, one patient showed two phenotypically different MRSA isolates from the same site and both isolates were included on the study. Two patients were positives only in groin and these isolates were evaluated as well. 
Table 1 Clinical and demographic characteristics of 190 patients before and after liver transplantation undergoing screening for methicillin-resistant S. aureus (MRSA)

\begin{tabular}{|c|c|c|}
\hline Characteristics & Cirrhotic Patients on the waiting list for liver transplantation (126) & Liver-transplanted patients (64) \\
\hline Male & $85(67 \%)$ & $37(58 \%)$ \\
\hline \multicolumn{3}{|l|}{ Age (years) } \\
\hline Median & 53 & 52 \\
\hline Range & 19-71 & $17-71$ \\
\hline \multicolumn{3}{|l|}{ Underlying diseases $^{a}$} \\
\hline Cirrhosis due to hepatitis C & $38(30 \%)$ & $10(16 \%)$ \\
\hline Alcoholic cirrhosis & $23(18 \%)$ & $8(12.5 \%)$ \\
\hline Cryptogenic cirrhosis & $13(10 \%)$ & $9(14 \%)$ \\
\hline Auto immune hepatites & $9(7 \%)$ & $2(3 \%)$ \\
\hline Cirrhosis due to hepatitis B & $8(6 \%)$ & $3(5 \%)$ \\
\hline Sclerosing cirrhosis & $5(4 \%)$ & $1(1.5 \%)$ \\
\hline Primary biliary cirrhosis & $4(3 \%)$ & $1(1.5 \%)$ \\
\hline Secondary biliary cirrhosis & $3(2 \%)$ & $2(3 \%)$ \\
\hline Nash (nonalcoholoic steatohepatitis) & $3(2 \%)$ & $1(1.5 \%)$ \\
\hline Fulminant hepatites & - & $4(6 \%)$ \\
\hline hepatocellular carcinoma & - & $3(5 \%)$ \\
\hline Unknown cause & $4(3 \%)$ & $14(22 \%)$ \\
\hline Other ${ }^{b}$ & $14(11 \%)$ & $8(13 \%)$ \\
\hline \multicolumn{3}{|l|}{ Site of colonization by MRSA } \\
\hline Nasal only & $8(50 \%)$ & $9(60 \%)$ \\
\hline Groin only & $2(12.5 \%)$ & $2(13 \%)$ \\
\hline Nasal and groin & $6(37.5 \%)$ & $4(27 \%)$ \\
\hline
\end{tabular}

${ }^{a}$ The total is greater than $100 \%$ because some patients had more than one disease

${ }^{\mathrm{b}}$ Other diseases related: Caroli's syndrome, schistosomiasis, alpha-1 antitrypsin deficiency, Wilson's syndrome, biliary atresia, Liver polycystic disease and familial amyloid polyneuropathy

A total of 32 isolates were selected for further molecular typing, which included 16 isolates from patients of the liver-transplant waiting list and 16 isolates from liver-transplanted patients.

\section{SCCmec and virulence factors}

Among the MRSA isolates, 6 (19 \%) carried SCCmec I, 18 (56 \%) SCCmec II, 5 (16 \%) SCCmec III and 3 (9 \%) SCCmec IVa. SCCmec types that are generally associated with nosocomial infections (SCCmec types I, II and III) were identified in $91 \%$ of the HA-MRSA isolates. Of these, SCCmec type II was the most prevalent type. None of the isolates carried PVL, adhesion factors such as exfoliating A, B (eta and etb genes) and fibrinogen binding protein (fib gene). Three MRSA isolates carried the tst gene, all isolates were characterized as SCCmec type I, belonged to cluster E and t0149 and were isolated from one cirrhotic patient and two liver-transplanted patients. None of patients carrying tst isolates developed infections.

\section{Spa typing}

Spa typing of the 32 tested MRSA isolates revealed nine known spa types (t002, t010, t037, t088, t110, t149, t311, t539 and t3824) and one isolate from a cirrhotic patient was characterized as a new spa type t14789. This new spa type presented the following SSR: (r26, r23, r17, r16, $\mathrm{r} 20, \mathrm{r} 17, \mathrm{r} 12, \mathrm{r} 17, \mathrm{r} 16)$, its present a deletion of repeat and a replacement of r34 by r16 comparing t002, and was closely related to $\mathrm{t} 311$ with a replacement of $\mathrm{r} 34$ by r16. Of these 9 spa types, t002 was the most common, representing $40.6 \%$ of all isolates.

\section{PFGE}

To define the Pulsed-Field types (PFT) obtained by PFGE, two cutoff levels were considered: $>80 \%$ to define types and $80-95 \%$ to define subtypes. The types were represented by capital letters and subtypes by numbers. Between the 32 MRSA isolates, 9 PFGE types and 19 PFGE subtypes were identified. The dendrogram revealed that 13 (41 \%) MRSA isolates belonged to a major cluster, the PFT A, which was related with the 
representative New York/Japan epidemic clone (NY/Jpn clone) BK2464, this predominant cloned was identified in cirrhotic outpatients $(n=8)$ and in posttransplantation patients $(N=5)$ and distributed over a year period (Fig. 2). Other smaller clusters were noted (PFT B, C D, E and F, G, H and I). The representative Brazilian epidemic clone (BEC) HSJ216 was related with 4 (12 \%) MRSA isolates with PFT F, all them carried the same spa type and SCCmec type (t037-SCCmec III) and were from post transplantation patients. The dendrogram, SCCmec, spa type and PFT were represented in Fig. 1.

The distribution of SCCmec, spa type and PFGE profiles among the pre and post transplantation patients can be seen in Table 2. Distribution of MRSA strains belonged to the predominant NY/Japanese clone isolated from cirrhotic and post -transplantation patients over the study period can be seen in Fig. 2 .

\section{MLST}

Five Sequence types (ST) were identified. The results of the MLST for isolates of each PFGE type (A to I) are presented in Table 3.

\section{Discussion}

Previous studies have shown that MRSA colonization in cirrhotic patients varies from 16 to $28 \%$ and that MRSA colonization can be associated with a high risk for 
Table 2 Association between molecular typing profiles and epidemic clones, spa types, SCCmec types and virulence factors in methicillin-resistant S. aureus isolates of cirrhotic and liver transplanted patients from August 2010 to December 2011

\begin{tabular}{|c|c|c|c|c|c|c|c|c|c|}
\hline \multirow[t]{2}{*}{ PFT } & \multirow{2}{*}{$\begin{array}{l}\text { Relationship with } \\
\text { Epidemic Clones }\end{array}$} & \multirow{2}{*}{$\begin{array}{l}\text { Spa type } \\
\text { (number } \\
\text { of } \\
\text { isolates) }\end{array}$} & \multirow{2}{*}{$\begin{array}{l}\text { SCCmec } \\
\text { type }\end{array}$} & \multicolumn{4}{|c|}{ Genes for Virulence factors } & \multirow[b]{2}{*}{ Cirrhotic } & \multirow[b]{2}{*}{ Liver transplantation } \\
\hline & & & & $\overline{P V L}$ & TST & lukDE & $f n P A$ & & \\
\hline $\mathrm{A} 1$ & NewYork/Japan clone & t002 (7) & $\|$ & $(-)$ & $(-)$ & $(+)$ & $(+)$ & 5 & 2 \\
\hline $\mathrm{A} 1$ & NewYork/Japan clone & t3824 (1) & $\|$ & $(-)$ & $(-)$ & $(+)$ & $(+)$ & - & 1 \\
\hline A1 & NewYork/Japan clone & $\mathrm{t} 149(1)$ & $\|$ & $(-)$ & $(-)$ & $(+)$ & $(+)$ & - & 1 \\
\hline A2 & NewYork/Japan clone & t539 (1) & $\|$ & $(-)$ & $(-)$ & $(+)$ & $(+)$ & 1 & - \\
\hline A3 & NewYork/Japan clone & t088 (1) & । & $(-)$ & $(-)$ & $(+)$ & $(+)$ & - & 1 \\
\hline A4 & NewYork/Japan clone & t002 (1) & $\|$ & $(-)$ & $(-)$ & $(+)$ & $(+)$ & 1 & - \\
\hline A5 & NewYork/Japan clone & t010 (1) & $\|$ & $(-)$ & $(-)$ & $(+)$ & $(+)$ & 1 & - \\
\hline B1 & & t311 (2) & $\|$ & $(-)$ & $(-)$ & $(+)$ & $(+)$ & 2 & - \\
\hline B2 & & t002 (1) & $\|$ & $(-)$ & $(-)$ & $(+)$ & $(+)$ & 1 & - \\
\hline$C$ & & t002 (1) & $\|$ & $(-)$ & $(-)$ & $(+)$ & $(+)$ & - & 1 \\
\hline D1 & & $\mathrm{t} 14789(1)$ & $\mathrm{IVa}$ & $(-)$ & $(-)$ & $(+)$ & $(+)$ & 1 & \\
\hline D2 & & t002 (1) & III & $(-)$ & $(-)$ & $(+)$ & $(+)$ & - & 1 \\
\hline D3 & & t002 (1) & $\mathrm{IVa}$ & $(-)$ & $(-)$ & $(+)$ & $(+)$ & - & 1 \\
\hline E1 & & t149 (1) & । & $(-)$ & $(+)$ & $(+)$ & $(+)$ & 1 & - \\
\hline E1 & & $\mathrm{t} 149$ (1) & 1 & $(-)$ & $(+)$ & $(-)$ & $(+)$ & - & 1 \\
\hline E2 & & t149 (1) & I & $(-)$ & $(+)$ & $(+)$ & $(+)$ & - & 1 \\
\hline E3 & & t088 (1) & $\|$ & $(-)$ & $(-)$ & $(+)$ & $(+)$ & - & 1 \\
\hline F1 & Brazilian clone & t037 (2) & III & $(-)$ & $(-)$ & $(+)$ & $(+)$ & - & 2 \\
\hline $\mathrm{F} 1$ & Brazilian clone & t037 (1) & III & $(-)$ & $(-)$ & $(-)$ & $(-)$ & - & 1 \\
\hline F2 & Brazilian clone & t037 (1) & III & $(-)$ & $(-)$ & $(+)$ & $(+)$ & - & 1 \\
\hline G & & $\mathrm{t} 110(2)$ & I & $(-)$ & $(-)$ & $(+)$ & $(+)$ & 1 & 1 \\
\hline $\mathrm{H}$ & & t002 (1) & $\|$ & $(-)$ & $(-)$ & $(+)$ & $(-)$ & 1 & - \\
\hline I & & $\mathrm{t} 149$ (1) & $\mathrm{IVa}$ & $(-)$ & $(-)$ & $(-)$ & $(-)$ & 1 & - \\
\hline
\end{tabular}

\section{$\square$ Patients of list to liver transplantation $\square$ liver transplanted patients}

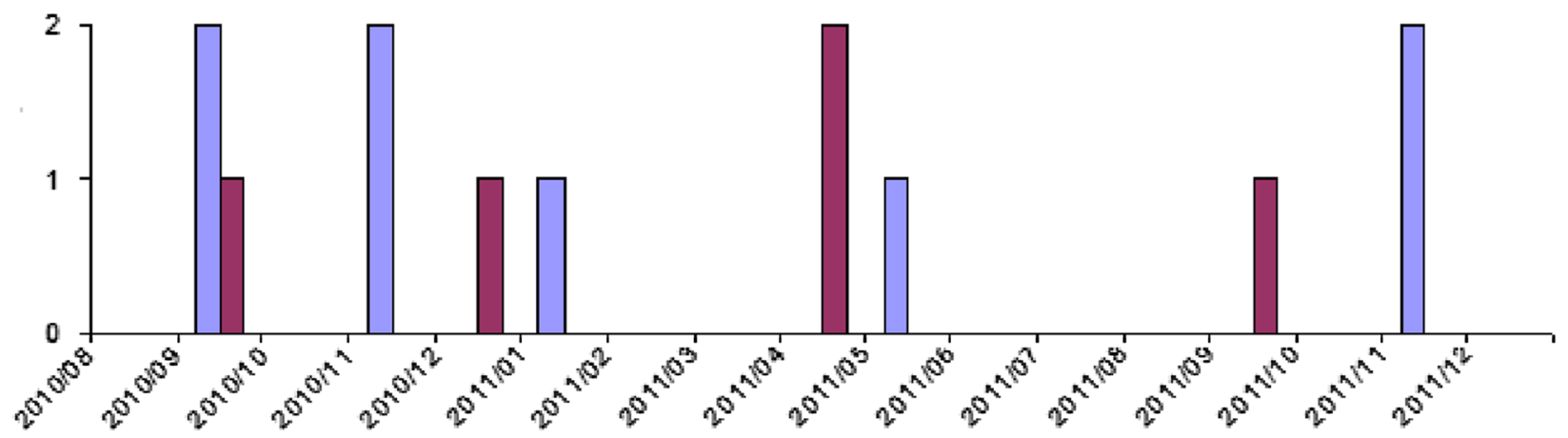

Fig. 2 Distribution of MRSA strains belonged to the predominant NY/Japanese clone isolated from cirrhotic and post-transplantation patients over the study period, from 2010 to 2012 
Table 3 Methicilin-resistant Staphylococcus aureus isolates evaluated as to their MLST. Comparison of Multi Locus Sequence Typing with PFT and Spa typing of Methicilin-resistant Staphylococcus aureus isolates over study period, from August 2010 to December 2011

\begin{tabular}{|c|c|c|c|c|c|}
\hline Isolates & Body site & spa type & sccmec & $\mathrm{ST}^{\mathrm{a}}$ & $\mathrm{PFT}^{\mathrm{b}}$ \\
\hline $27 N$ & nasal & t002 & $\|$ & ST105 & A1 \\
\hline $08 \mathrm{~N}$ & nasal & t311 & $\|$ & ST105 & B1 \\
\hline P65N & nasal & t002 & $\|$ & ST105 & C \\
\hline 981 & groin & t14789 & $\mathrm{IVa}$ & ST1176 & D1 \\
\hline $62 \mathrm{~N}$ & nasal & $\mathrm{t} 149$ & I & ST5 & E1 \\
\hline P32N & nasal & $\mathrm{t} 37$ & III & ST239 & $\mathrm{F} 1$ \\
\hline $78 \mathrm{~N}$ & nasal & $\mathrm{t} 110$ & I & ST105 & G \\
\hline $111 \mathrm{~N}$ & nasal & t002 & $\|$ & ST105 & $\mathrm{H}$ \\
\hline $59 \mathrm{~N}$ & nasal & t149 & $\mathrm{IVa}$ & ST1510 & I \\
\hline
\end{tabular}

${ }^{\mathrm{a}} \mathrm{ST}$ sequence type, ${ }^{\mathrm{b}}$ Pulsed-field typing

infection in post liver transplantation patients [11-14]. In spite of this, few studies evaluated the molecular characterization of MRSA in liver transplantation patients, most of them described outbreaks, only $p v l$ was evaluated among the virulence factors, and no study compared PFGE with spa typing [14-16]. To our knowledge, this is the first prospective study of molecular characterization of MRSA isolates in patients before and after liver transplantation.

MRSA decolonization has been recommending pre surgery in high risk patients such as cardiac and orthopedic patients. However, data in liver transplantation is scarce; most of studies of MRSA carriage in post liver transplanted patients were retrospective, evaluated only nares $[13,17,18]$ and the efficacy of pre surgery decolonization need to be better addressed. In our study, a high proportion of swabbed patients were colonized with MRSA, and nares were the most frequent site of colonization. We did not identify outbreak due to MRSA in our hospital during the study period which might impact the colonization rates, however, MRSA screening is not performed as routine in the high risk patients such as intensive care patients, thus, MRSA colonization was underreported.

A previous study also showed that 236 nares (46\%) were more positives than rectal cultures $(18 \%)$. Based on our results it seems that there is no need to collected cultures of other sites besides nares to screening MRSA in cirrhotic or liver transplanted patient. Although not significant, in our study liver transplanted patients were more likely to be colonized by MRSA than cirrhotic patients $(p=0.091)$. Thirty-three percent of the MRSA isolates were from transplanted patients and $17 \%$ of isolates were from cirrhotic patients. However, only three patients colonized developed infection due to MRSA post-transplantation, and one patient presented the same cluster NY/Jpn in colonization and infection. In contrast, during the period of this study, there were outbreaks by Gram-negative bacteria in the liver transplantation unit of our hospital [19]. Interesting, none of patients colonized with MRSA harboring tst gene developed infections. It seems that the high rate of MRSA colonization did not increase the rate of infection.

Regarding the molecular typing data we identified nine different Pulsed Field Types (A-I). The cluster A was predominant (41\%) and related to the NY/Jpn clone and present in cirrhotic and liver transplanted patients. Only $12.5 \%$ of MRSA isolates belonged to BEC that was identified only in post transplanted patients. Nine known spa types and a new spa typing (t14789) were identified. Among them, spa type t002 was the most frequent, six spa types were associated with the New York/Japan clone (t002, t010, t088, t149, t539 and t3824) and the spa type 037 was associated with BEC. These data was similar with studies that showed that in the last decade, the New York/Japan clone was highly prevalent in many Brazilian hospitals [20-23]. In contrast until 2005, MRSA isolates SCCmec Iva (57 \%) and SCCmec type III belonged to and the Brazilian Endemic Clonal Complex (BECC) (39 \%) were predominant in our hospital [23]. However, since 2010, there was a switched of pattern in our hospital, MRSA isolates SCCmec II (60 \%) with characteristics of $\mathrm{NY} / \mathrm{Jpn}$ clone were predominant instead of MRSA isolates belonged to BEC that represent only $10 \%$ of isolates [22].

In our study, none of MRSA isolates associated with the $\mathrm{NY} /$ Jpn clone carry tst gene and $92 \%$ harbored SCCmec II (only one isolate carried SCCmec I). Interestingly, all MRSA isolates with tst gene carried the same spa type and SCCmec (t0149 - SCCmec I) but belonged to the different PFT E and differ from Japanase studies [24, 25]. The major MRSA distributed among Japanese hospitals is New York / Japan clone with SCCmec II and generally carries the tst gene [24, 25]. However, American studies showed that isolates of MRSA USA100 (associated with $\mathrm{NY} /$ Jpn clone) harbor SCCmec II and rarely carry tst gene [24-26]. In view of these results, our MRSA isolates belonged to $\mathrm{NY} / \mathrm{Jpn}$ clone seen be more similar to the USA100 MRSA isolates.

In the present study, only $4(12,5 \%)$ isolates showed a pattern closely related to the BEC. All of them had the same spa type (t037) and SCCmec type III. About the virulence profile, one isolate did not have the same pattern of virulence than otherisolates. Although there are few studies with spa typing in Brazil, our findings are similar to other Brazilian studies that also found that MRSA isolates t037-SCCmec III were strongly related with Brazilian epidemic clone $[27,28]$. On the other hand, a new spa type 14789 was identified in our study in a cirrhotic patient as well as 6 spa types t010, t088, t149, t311, t539 e $\mathrm{t} 3824$ that were identified for the first time in Brazil. 
This study has several limitations such as it was performed in only one center, the low number of MRSA infection in the post liver transplantation patients did not allow us to compare the virulence among colonization and infection strains and to conduct an intervention study with decolonization with mupirocin and chlorhexidine bath. Unfortunately, we could not perform MLST for all isolates. However, among the STs identified in our study, ST5, ST105, ST239 and ST1176 had already been reported in Brazil [21-23, 27-29], including studies in our Hospital [22, 23]. Nevertheless it was the first description of ST1510 in Brazil.

In this study, PFGE had a greater discriminatory power than spa typing. Furthermore, isolates within the same PFGE cluster had different spa types. Golding and colleagues [10] developed a large study in Canada with MRSA isolates and showed that spa types were not limited to a specific PFGE pattern, and that indistinguishable PFGE patterns could be of different spa types. These authors made a more detailed analysis of SSR based on the degree of similarity of spa types, and showed six-spa clonal complexes that were related to specific epidemic clones. Thus, it is possible to suggest that further studies on the similarity between the SSR are needed to establish a more reliable correlation between PFGE patterns [10].

\section{Conclusion}

In conclusion, a high proportion of patients were colonized with MRSA and nares were the most frequent site of colonization. Liver-transplantation patients were more frequently colonized by MRSA than cirrhotic patients. SCCmec type II was the most frequent SCCmec, and the predominant clone was related to the $\mathrm{NY} / \mathrm{Jpn}$ cluster. PFGE showed a greater discriminatory power than spa typing. We identified a new spa t14789 and spa types and ST never reported in Brazil.

\section{Methods}

\section{Ethics statement}

The study was performed from August 2010 to December 2011 in a university hospital located in São Paulo, Brazil, the Central Institute of Hospital das Clínicas of University of São Paulo (ICHC-FMUSP). All patients filled out a written form agreeing to participate in this study, which was approved by the ethics committee of "Hospital das Clinicas" and Medical University of Sao Paulo. The approval number is 0307/09.

\section{Study design}

Prospective observational study, one isolate per patient was selected for further molecular typing. When patients showed MRSA isolates from the both sites with the same PFGE, the nasal MRSA isolate was choose for next steps.

\section{Population}

Nasal and groin swabs were collected from patients on the waiting list for liver transplantation who came to medical appointments or were hospitalized in the liver transplant unit. Swabs of liver-transplanted patients were also collected on the first day after to surgery or within $48 \mathrm{~h}$ after transplantation. Data from nosocomial infections due to MRSA during hospitalization and until 30 days post-transplantation were evaluated.

All patients agreed to participate in the 335 study. Demographic and clinical data of patients were collected by a prior questionnaire and chart reviews. A data base was build using Epi Info (version 3.5.1), and proportion of MRSA colonization among cirrhotic and liver transplantation patients was compared using chi-square test, $p$ value $<0.05$ was consider significant.

\section{MRSA identification}

The swabs (BAC SWAB $1002 \mathrm{DME}^{\circ}$ ) were cultured in accordance with protocols previously described [30, 31]. Strains were identified as MRSA according to screening Oxacillin resistance as recommended by CLSI (Clinical Laboratory Standards Institute) 2010.

\section{DNA extraction}

The DNA genomic extraction was performed by Illustra Bacteria Genomicprep Mini Spin ${ }^{\circ}$ (Ge Healthcare Life Science, USA) according to the manufacturer's instructions.

\section{Multiplex PCR for Detection of mecA and $\operatorname{CoA}$ genes}

A multiplex PCR (M-PCR) was performed to confirm methicillin resistance of the $S$. aureus isolates. The MPCR amplifies the coagulase gene $c o A$ (intrinsic to $S$. aureus) and the mecA gene which confers resistance to methicillin. PCR was performed according protocol described previously [32].

\section{Determination of $\mathrm{SCCmec}$}

The determination of SCCmec types was performed using the M-PCR method as described by Zhang et al. [6], with this method it was possible to determine SCCmec types I, II, III, IVa, IVb, IVc, IVd and V.

\section{Virulence factors}

Specific genes ( $c l f \mathrm{~B}, f i b, f n b \mathrm{PA}, e t a, e t b, l u k$-DE, $p v l$ and tst) which encode adhesins and toxins in $S$. aureus were identified by M-PCR according to the protocol described previously [33].

\section{Spa typing}

The amplification of the polymorphic region $\mathrm{X}$ of the spa gene was performed with chromosomal DNA purified from each isolate using primers designed by Shopsin 
and colleagues [8]. The amplified products were sent to the Human Genome Research Center of University of São Paulo for sequencing. The sequences were analyzed using Bioedit software (version 7.2.5; Ibis Biosciences, CA). Lastly, the spa type was determined using the online software spaTyper (http://spatyper.fortinbras.us/) and confirmed on SpaServer database (http://www.spase rver.ridom.de/) in the National Microbiology Laboratory of Canada, Winnipeg, Manitoba, Canada.

\section{PFGE}

The chromosomal DNA of MRSA isolates was digested using the restriction enzyme SmaI (Amersham Pharmacia Biotech, USA). Pulsed-field gel electrophoresis was performed using a CHEF DR-II system (Bio-Rad, USA) according to previously described [34]. PFGE patterns were analyzed in Bionumerics version 7.1 (Applied-Maths, Sint-Martens-Latem, Belgium). DNA fragments were manually curated and normalized using the molecular weight standard run on each gel. A 1,5\% band tolerance and optimization of $0,5 \%$ was selected for use during comparisons of DNA profiles as suggested by Mulvey and colleagues [35]. Cluster analysis was performed by the unweighted pair group method using arithmetic averages (UPGMA). Isolates were considered to be genetically related if Dice coefficient correlation was $>80 \%$. DNA fragments of the strains BK2464 and HSJ216 (representative of New York/Japan epidemic clone and Brazilian epidemic clone, respectively) were included to comparisons of DNA profiles according to PFGE patterns previously generated by Oliveira and colleagues [34].

\section{MLST}

Nine isolates were selected, one isolate of each PFT to performed MLST profiles according to procedures published elsewhere [36]. The sequences of seven housekeeping genes $(\operatorname{arc} \mathrm{C}, \operatorname{aro\mathrm {E}}, g l p \mathrm{~F}, g m k, p t a, t p i$ and $y q i \mathrm{~L}$ ) were compared to existing sequences in the MLST database (http:// www.mlst.net) for the assignment of allelic numbers. Sequence types (ST) were assigned according to their allelic profiles.

\footnotetext{
Abbreviations

S. aureus: Staphylococcus aureus; MRSA: Methicillin-resistant Staphylococcus aureus; PVL: Panton-Valentine leucocidin; SCCmec: Staphylococcal Chromosome Cassette mec; PCR: Polymerase Chain Reaction; MLST: Multi Locus Sequence Typing; ST: Sequence type; PFGE: Pulsed-Field Gel Electrophoresis; PFT: Pulsed-Field type; SSR: Short-sequence repeat; NY/Jpn clone: New York/Japan epidemic clone; BEC: Brazilian epidemic clone; DNA: Deoxyribonucleic acid; M-PCR: Multiplex PCR.
}

\section{Competing interest}

The authors declare that they have no conflict of interest.

\section{Authors' contributions}

LMO, ASL and SFC designed the study. LMO, IMV and MPF collected the samples. LMO and IMV carried out the laboratory work. LMO, FR, EA, LAC
AC ASL and SFC analyzed the data. LMO, IMV and SFC wrote the manuscript. All authors read and approved the final version of manuscript.

\section{Acknowledgments}

The authors are grateful to financial support by FAPESP (Fundação de Amparo à pesquisa do Estado de São Paulo) and CNPQ (Conselho Nacional de Desenvolvimento Científico e Tecnológico).

\section{Author details}

${ }^{1}$ Department of Infection Control, Hospital das Clínicas, University of São Paulo, São Paulo, Brazil. 'Laboratory of Medical Investigation 54 (LIM-54), Hospital Das Clínicas FMUSP, São Paulo, Brazil. ${ }^{3}$ National Microbiology Laboratory, Winnipeg, Manitoba, Canada. ${ }^{4}$ Liver Transplantation Unit, Hospital das Clinicas, University of São Paulo, São Paulo, Brazil. 'Laboratory of Microbiology, Hospital das Clinicas, University of São Paulo, São Paulo, Brazil. ${ }^{6}$ Department of Infectious Diseases, LIM-54, Faculdade de Medicina, University of São Paulo, Avenida Doutor Enéas de Carvalho Aguiar, 470, São Paulo, SP 05403-000, Brazil.

Received: 4 June 2015 Accepted: 3 November 2015

Published online: 14 November 2015

\section{References}

1. DeLeo FR, Chambers HF. Reemergence of antibiotic resistant Staphylococcus aureus in the genomics era. J Clin Invest. 2009;119:2464-74.

2. Gales AC, Sader HS, Ribeiro J, Zoccoli C, Barth A, Pignatari AC. Antimicrobial susceptibility of gram-positive bacteria isolated in Brazilian hospitals participating in the SENTRY Program (2005-2008). Braz J Infect Dis. 2009;13:90-8.

3. Schneider CR, Buell JF, Gearhart M, Thomas M, Hanaway MJ, Rudich SM, et al. Methicillin-resistant Staphylococcus aureus infection in liver transplantation: a matched controlled study. Transplant Proc. 2005;37(2):1243-4.

4. Fagiuoli S, Colli A, Bruno R, Craxì A, Gaeta GB, Grossi P, et al. Management of infections pre- and post-liver transplantation: Report of a AISF Consensus Conference. J Hepatol. 2013;60(5):1075-89.

5. Kobayashi SD, DeLeo FR. An update on community associated MRSA virulence. Curr Opin Pharmacol. 2009;9(5):545-51.

6. Zhang K, McClure J, Elsayed S, Louie T, Conly JM. Novel multiplex PCR assay for characterization and concomitant subtyping of staphylococcal cassette chromosome mec Types I to V in methicillin-resistant Staphylococcus aureus. J Clin Microbiol. 2005;43(10):5026-33.

7. Trindade PA, McCulloch JA, Oliveira GA, Mamizuka EM. Molecular techniques for MRSA typing: Current issues and perspectives. Braz J Infect Dis. 2003;7:32-43.

8. Shopsin B, Gomez M, Montgomery SO, Smith DH, Waddington M, Dodge DE, et al. Evaluation of protein A gene polymorphic region DNA sequencing for typing of Staphylococcus aureus strains. J Clin Microbiol. 1999;37:3556-63.

9. Hallin M, Deplano A, Denis O, De Mendonça R, De Ryck R, Struelens MJ. Validation of pulsed-field gel electrophoresis and spa typing for long term, nationalwide epidemiological surveillance studies of Staphylococcus aureus infections. J Clin Microbiol. 2007:45(1):127-33.

10. Golding GR, Campbell JL, Spreitzer DJ, Veyhl J, Surynicz K, Simor A, et al. A preliminary guideline for the assignment of methicillin-resistant Staphylococcus aureus to a Canadian pulsed-field gel electrophoresis epidemic type using spa typing. Can J Infect Dis Med Microbiol. 2008;19(4):273-81.

11. Chang FY, Singh N, Gayowski T, Wagener MM, Marino IR. Staphylococcus aureus nasal colonization in patients with cirrhosis: prospective assessment of association with infection. Infect Control Hosp Epidemiol. 1998;19(5):328-32.

12. Dupeyron C, Campillo SB, Mangeney N, Richardet JP, Leluan G. Carriage of Staphylococcus aureus and of gram-negative bacilli resistant to thirdgeneration cephalosporins in cirrhotic patients: a prospective assessment of hospital-acquired infections. Infect Control Hosp Epidemiol. 2001;22(7):427-32.

13. Desai D, Desai N, Nightingale P, Elliott T, Neuberger J. Carriage of methicillin-resistant Staphylococcus aureus is associated with an increased risk of infection after liver transplantation. Liver Transpl. 2003;9(7):754-9.

14. Romanelli RM, Clemente WT, Lima SS, Rezende EM, Martinho GH, Paiva LF, et al. MRSA outbreak at a transplantation unit. Braz J Infect Dis. 2010;14(1):54-9.

15. Hamson C, Walton KE, Collins J, Wilson L, Perry JD, Al-Zahrani IA, et al. Report of an outbreak of CO2-dependent methicillin-resistant Staphylococcus aureus on a regional liver transplant unit. J Antimicrob Chemother. 2011;66(5):1179-81. 
16. Obed A, Schnitzbauer AA, Bein T, Lehn N, Linde HJ, Schlitt HJ. Fatal pneumonia caused by Panton-Valentine Leucocidine-positive methicillinresistant Staphylococcus aureus (PVL-MRSA) transmitted from a healthy donor in living-donor liver transplantation. Transplantation. 2006;81(1):121-4.

17. Hashimoto M, Sugawara Y, Tamura S, Kaneko J, Matsui Y, Moriya K, et al. Impact of new methicillin-resistant Staphylococcus aureus carriage postoperatively after living donor liver transplantation. Transplant Proc. 2007:39(10):3271-5.

18. Singh N, Squier C, Wannstedt C, Keyes L, Wagener MM, Cacciarelli TV. Impact of an aggressive infection control strategy on endemic Staphylococcus aureus infection in liver transplant recipients. Infect Control Hosp Epidemiol. 2006;27(2):122-6.

19. Freire MP, Van Der Heijden IM, do Prado GV, Cavalcante LS, Boszczowski I, Bonazzi PR, et al. Polymyxin use as a risk factor for colonization or infection with polymyxin-resistant Acinetobacter baumannii after liver transplantation. Transpl Infect Dis. 2014;16(3):369-78.

20. Melo MC, Silva-Carvalho MC, Ferreira RL, Coelho LR, Souza RR, Gobbi CN, et al, Detection and molecular characterization of a gentamicin-susceptible, methicillin-resistant Staphylococcus aureus (MRSA) clone in Rio de Janeiro that resembles the New York/Japanese clone. J Hosp Infect. 2004;58(4):276-85.

21. de Miranda OP, Silva-Carvalho MC, Ribeiro A, Portela F, Cordeiro RP, Caetano N, et al. Emergence in Brazil of methicillin-resistant Staphylococcus aureus isolates carrying SCCmecIV that are related genetically to the USA800 clone. Clin Microbiol Infect. 2007;13(12):1165-72.

22. Caiaffa-Filho HH, Trindade PA, da Cunha Gabriela P, Alencar CS, Prado GV, Rossi F, et al. Methicillin-resistant Staphylococcus aureus carrying SCCmec type II was more frequent than the Brazilian endemic clone as a cause of nosocomial bacteremia. Diagn Microbiol Infect Dis. 2013;76(4):518-20.

23. Pacheco RL, Lobo RD, Oliveira MS, Farina EF, Santos CR, Costa SF, et al, Methicillin-resistant Staphylococcus aureus (MRSA) carriage in a dermatology unit. Clinics. 2011;66(12):2071-7.

24. Zaraket H, Otsuka T, Saito K, Dohmae S, Takano T, Higuchi W, et al. Molecular characterization of methicillin-resistant Staphylococcus aureus in hospitals in Niigata, Japan: divergence and transmission. Microbiol Immunol. 2007:51(2):171-6.

25. Yanagihara K, Morinaga Y, Matsuda J. Genetic diagnosis of community-acquired MRSA: a multiplex real-time PCR method for Staphylococcal cassette chromosome mec typing and detecting genes. X - Tohoku. J Exp Med. 2010;220(2):165-70.

26. Tenover FC, McAllister S, Fosheim G, McDougal LK, Carey RB, Limbago B, et al. Characterization of Staphylococcus aureus isolates from nasal cultures collected from individuals in the United States in 2001 to 2004. J Clin Microbiol. 2008;46(9):2837-41

27. Lamaro-Cardoso J, de Lencastre H, Kipnis A, Pimenta FC, Oliveira LS, Oliveira RM, et al. Molecular epidemiology and risk factors for nasal carriage of staphylococcus aureus and methicillin-resistant S. Aureus in infants attending Day care centers i 598 n brazil. J Clin Microbiol. 2009:47(12):3991-7.

28. Vieira MA, Minamisava R, Pessoa-Júnior V, Abraão LM, Patrícia YF, Martins PYE, et al. Methicillin-resistant Staphylococcus aureus nasal carriage in neonates and children attending a pediatric outpatient clinics in Brazil. Braz J Infect Dis. 2013;18(1):42-7.

29. Lima DF, Brazão NB, Folescu TW, Neves FP, Ferreira AG, Santos EA, et al. Valentine leukocidin (PVL) gene carriage among Staphylococcus aureus strains with SCCmec types I, III, IV, and V recovered from cystic fibrosis pediatric patients in Brazil. Diagn Microbiol Infect Dis. 2014;78(1):59-62.

30. Mir N, Sánches M, Baquero F, López B, Calderón C, Cantón R. Soft salt-mannitol agar-cloxacillin test: a highly specific bedside screening test for detection of colonization with methicillin-resistant staphylococcus aureus. J Clin Microbiol. 1998:36:986-9.

31. Bocher S, Middendorf B, Westh H, Mellmann A, Becker K, Skov R, et al. Semi-selective broth improves screening for methicillin-resistant Staphylococcus aureus. J Antimicrob Chemother. 2010;65:717-20.

32. Kearns AM, Seiders PR, Wheeler J, Freeman R, Steward M. Rapid detection of methicillin-resistant staphylococci by multiplex PCR. J Hosp Infect. 1999:43(1):33-7.

33. Baba-Moussa L, Anani L, Scheftel JM, Keller D, Bankolé H, Barogui Y, et al. Virulence factors produced by strains of Staphylococcus aureus isolated from urinary tract infections. J Hosp Infect. 2008;68(1):32-8.
34. Oliveira GA, Faria JB, Levy CE, Mamizuka EM. Characterization of the Brazilian endemic clone of methicillin resistant Staphylococcus aureus (MRSA) from hospitals throughout Brazil. Braz J Infect Dis. 2001;5:163-70.

35. Mulvey MR, Chui L, Ismail J, Louie L, Murphy C, Chang N, et al. Canadian committee for the standardization of molecular methods. Development of a Canadian standardized protocol for subtyping methicillin-resistant staphylococcus aureus using pulsed-field gel electrophoresis. J Clin Microbiol. 2001;39(10):3481-5

36. Enright MC, Day NP, Davies CE, Peacock SJ, Spratt BG. Multilocus sequence typing for characterization of methicillin-resistant and methicillin-susceptible clones of Staphylococcus aureus. J Clin Microbiol. 2000;38(3):1008-15.

\section{Submit your next manuscript to BioMed Central and take full advantage of:}

- Convenient online submission

- Thorough peer review

- No space constraints or color figure charges

- Immediate publication on acceptance

- Inclusion in PubMed, CAS, Scopus and Google Scholar

- Research which is freely available for redistribution 